\title{
Article \\ Modification of Homologous Recombination Deficiency Score Threshold and Association with Long-Term Survival in Epithelial Ovarian Cancer
}

\author{
Jeffrey A. How ${ }^{1}{ }^{(0}$, Amir A. Jazaeri ${ }^{1}$, Bryan Fellman ${ }^{2}$, Molly S. Daniels ${ }^{3}$, Suzanna Penn ${ }^{4}$, Cara Solimeno ${ }^{4}$, \\ Ying Yuan ${ }^{2}$, Kathleen Schmeler ${ }^{1}$, Jerry S. Lanchbury ${ }^{4}$, Kirsten Timms ${ }^{4}$, Karen H. Lu ${ }^{1}$ and Melinda S. Yates ${ }^{1, *(D)}$ \\ 1 Department of Gynecologic Oncology and Reproductive Medicine, the University of Texas MD Anderson \\ Cancer Center, Houston, TX 77030, USA; jahow@mdanderson.org (J.A.H.); \\ aajazaeri@mdanderson.org (A.A.J.); kschmele@mdanderson.org (K.S.); khlu@mdanderson.org (K.H.L.) \\ 2 Department of Biostatistics, the University of Texas MD Anderson Cancer Center, Houston, TX 77030, USA; \\ BMFellman@mdanderson.org (B.F.); yyuan@mdanderson.org (Y.Y.) \\ 3 Department of Clinical Cancer Genetics, the University of Texas MD Anderson Cancer Center, Houston, \\ TX 77030, USA; msdaniel@mdanderson.org \\ 4 Myriad Genetics, Salt Lake City, UT 84108, USA; schau@myriad.com (S.P.); csolimen@myriad.com (C.S.); \\ jlanchbu@myriad.com (J.S.L.); ktimms@myriad.com (K.T.) \\ check for \\ * Correspondence: msyates@mdanderson.org
} updates

Citation: How, J.A.; Jazaeri, A.A.; Fellman, B.; Daniels, M.S.; Penn, S.; Solimeno, C.; Yuan, Y.; Schmeler, K.; Lanchbury, J.S.; Timms, K.; et al. Modification of Homologous Recombination Deficiency Score Threshold and Association with Long-Term Survival in Epithelial Ovarian Cancer. Cancers 2021, 13, 946. https: / / doi.org/10.3390/ cancers13050946

Academic Editors: Kimberly K. Leslie, David G. Mutch, Doris M. Benbrook and Kristina W. Thiel

Received: 1 February 2021

Accepted: 19 February 2021

Published: 24 February 2021

Publisher's Note: MDPI stays neutral with regard to jurisdictional claims in published maps and institutional affiliations.

Copyright: (c) 2021 by the authors. Licensee MDPI, Basel, Switzerland. This article is an open access article distributed under the terms and conditions of the Creative Commons Attribution (CC BY) license (https:// creativecommons.org/licenses/by/ $4.0 /)$.
Simple Summary: Knowledge of ovarian cancer molecular characteristics is increasingly crucial to individualizing and optimizing treatment strategies for this heterogeneous disease. Molecular features such as germline or somatic mutations, homologous recombination deficiency (HRD) status, microsatellite instability, and tumor mutational burden are associated with increased susceptibility to poly-ADP ribose polymerase inhibitors (PARPi) or immunotherapy. Our aim was to characterize these molecular features among ovarian cancer patients and determine their association with survival. Two different HRD score thresholds were evaluated: one currently used in clinics $(\geq 42)$ and another proposed as a new threshold $(\geq 33)$. An HRD score $\geq 33$ was associated with improved overall survival in ovarian cancer. As HRD assays are increasingly used for treatment planning, future studies should evaluate an HRD score threshold of $\geq 33$ compared to the currently used threshold of $\geq 42$ for PARPi use.

Abstract: New therapies, such as poly-ADP ribose polymerase inhibitors (PARPi), and immunotherapy treatments have generated great interest in enhancing individualized molecular profiling of epithelial ovarian cancer (EOC) to improve management of the disease. In EOC patients, putative biomarkers for homologous recombination deficiency (HRD), microsatellite instability (MSI), and tumor mutational burden (TMB) were characterized and correlated with survival outcomes. A series of 300 consecutive EOC patients were enrolled. Patients underwent neoadjuvant chemotherapy $(n=172)$ or primary cytoreductive surgery $(n=128)$. Molecular profiling and survival analyses were restricted to the primary cytoreductive surgery cohort due to tissue availability. All patients underwent germline testing for HRD- and MSI-related gene mutations. When sufficient tissue was available, screening for somatic BRCA1/2 mutations, BRCA1 promoter methylation, HRD score (a measure of genomic instability), MSI, and TMB testing were performed. HRD score $\geq 33$ was associated with improved overall survival on multivariable analysis. In the era of biomarker-driven clinical care, HRD score $\geq 33$ may be a useful adjunctive prognostic tool and should be evaluated in future studies to predict PARPi benefits.

Keywords: epithelial ovarian cancer; homologous recombination deficiency; homologous recombination deficiency score; microsatellite instability; tumor mutational burden; survival 


\section{Introduction}

Epithelial ovarian cancer (EOC) is the most deadly gynecologic malignancy, responsible for an estimated 13,940 deaths annually in the United States [1]. Historically, EOC has been clinically managed as one homogeneous entity with a combination of surgical cytoreduction and platinum-taxane chemotherapy [2-4]. However, histologic subtypes of EOC demonstrate significant biologic and genetic differences that impact their susceptibility to cytotoxic chemotherapy and targeted agents [2]. The most common EOC histologic subtype is high-grade serous (HGS) carcinoma (70\% of EOC cases), with the remainder being low-grade serous, clear cell, endometrioid, and mucinous [5]. Additionally, in profiling the molecular landscape of ovarian tumors, the Cancer Genome Atlas (TCGA) identified distinct molecular features between histologic subtypes. For example, HGS tumors had near universal TP53 gene mutations (96\%), with half containing abnormalities in the homologous recombination (HR) pathway [6]. Focusing on unique molecular features of EOC can provide the foundation to advance clinical management beyond the historical one-size-fits-all approach and improve long-term clinical outcomes.

Exploiting defects in the HR pathway has transformed clinical management of EOC and has placed emphasis on the development of reliable molecular assays to identify the presence of HR defects. The HR pathway is a set of critical DNA damage response mechanisms that protect genomic stability through high-fidelity repair of double-stranded DNA breaks $[5,7,8]$. Among a number of HR pathway protein factors, BRCA1 and BRCA2 proteins are critical to the integrity of the HR repair response. BRCA1 is a versatile protein that complexes with a number of proteins in the BRCA1-associated genome surveillance complex in order to link the detection of double-stranded DNA breaks and DNA damage repair effectors $[5,8,9]$. The main function of the BRCA2 protein is recruitment of RAD51 to regions of double-stranded breaks for HR repair $[5,8,10]$. With defective HR pathway proteins, cells with homologous recombination deficiency (HRD) are more susceptible to the intra- and interstrand crosslinking action of platinum agents [11,12]. Furthermore, HRD has become an attractive target for poly-ADP ribose polymerase inhibitors (PARPi) due to mechanisms of synthetic lethality and/or PARP trapping [5,13-15]. Given the crucial involvement of BRCA1 and BRCA2 proteins in the HR pathway, PARPi treatment in patients with BRCA1/2 mutations has significantly improved progression-free survival (PFS), thereby dramatically changing the landscape for EOC management [16-19]. Given this clinical benefit, expanding the scope of PARPi use through the identification of other biomarkers of HRD has been a particular focus of research [5,15]. In addition to germline and somatic BRCA1/2 mutations, other HRD markers include BRCA1 promoter methylation and other HR-related gene mutations (e.g., ATM, BARD1, BRIP1, CHEK2, NBN, PALB2, RAD51C, and RAD51D) $[5,20]$. Another assay that has garnered strong interest is the combined homologous recombination deficiency score (HRD score) [19,21-25]. HRD score is an unweighted sum of three independent DNA-based measures of genomic instability (loss of heterozygosity, telomeric allelic imbalance, and large-scale transitions) in the tumor $[19,21-25]$. A high HRD score $(\geq 42)$ has been shown to be predictive of clinical benefit with PARPi therapy, independent of BRCA1/2 status [26,27].

Immunotherapy also holds promise to revolutionize management of EOC and improve clinical outcomes, but again, requires robust and clinically feasible molecular assays to define key features and predict treatment response. Tumor molecular features, such as microsatellite instability (MSI), increase tumor immunogenicity and are strongly predictive of response to immune checkpoint inhibitors [28]. Microsatellites are repeated segments of DNA that are prone to DNA replication errors and these errors are typically corrected by DNA mismatch repair (MMR) proteins [29]. Nonfunctional or absent MMR proteins result in a substantial increase in mutations in the microsatellite regions, a condition called microsatellite instability [29]. Given this genetic hypermutable state, MSI or MMR-deficient tumors produce a greater neoantigen load and elicit a stronger antitumor immune response compared to microsatellite stable or MMR-proficient tumors [29]. Marabelle et al. reported improved objective response rates among patients with recurrent 
MSI or MMR-deficient EOC tumors treated with pembrolizumab [30,31]. Given this clinical benefit, pembrolizumab was approved for use in MSI or MMR-deficient solid tumors in 2017, signifying the first tissue-agnostic indication for a drug. Furthermore, high tumor mutational burden (TMB), a measure of the number of gene mutations within the tumor, has been cited as a predictive biomarker for response to immune checkpoint inhibitors [32].

Given the clinical importance of molecular profiling for HRD, MSI, and TMB, we developed a consecutive series of cases of EOC to conduct both molecular characterization and collect extensive clinical follow-up data. With this powerful cohort and molecular assays, we evaluated the association of these biomarkers and other clinical prognostic factors with survival outcomes.

\section{Materials and Methods}

\subsection{Patient Population}

Under a protocol approved by the institutional review board, a consecutive series of 300 EOC patients undergoing frontline treatment $(01 / 2010$ to $12 / 2013)$ were prospectively enrolled for tumor and germline BRCA1/2 characterization and additional tumor analyses. Cases included patients at MD Anderson Cancer Center and Lyndon B. Johnson General Hospital (treatment provided by the same gynecologic oncology attending faculty at both sites). The study inclusion criteria were the following: suspected or biopsy-proven epithelial ovarian, fallopian tube, or primary peritoneal cancer with adequate tumor specimen collection (>0.5 g) and/or willing to have blood sample collection for molecular testing. Exclusion criteria included patients presenting for treatment of recurrent disease or mucinous or borderline histologic subtypes. Tumors were classified as HGS histology if they contained a HGS component-this classification consisted of tumors with uniform HGS histology or mixed histology (e.g., endometrioid and HGS components). Chemotherapeutic regimens for patients undergoing primary cytoreductive surgery (PCS) or neoadjuvant chemotherapy (NACT) consisted of platinum (carboplatin or cisplatin) and taxane agents (paclitaxel or docetaxel). Due to limited tissue availability of specimens from pretreatment tumor biopsies for patients undergoing NACT, molecular characterization of tumor samples focused on patients who underwent PCS. Due to this limitation, while overall cohort characteristics are described (Table 1), the scope of the molecular evaluation was restricted to the PCS subpopulation.

\subsection{Blood Sample Collection and Molecular Testing}

Blood samples were collected perioperatively to perform germline testing for BRCA1/2 mutations and other genes involved in the HR pathway, including: ATM, BARD1, BRIP1, CHEK2, NBN, PALB2, RAD51C, and RAD51D. Other genes included in the genomic panel were the following: APC, BMPR1A, CDH1, CDK4, CDKN2A, EPCAM, MLH1, MSH2, MSH6, MUTYH, PMS2, PTEN, SMAD4, STK11, and TP53. Germline mutations that were deleterious or suspected deleterious were considered to be clinically significant mutations. Genomic DNA was extracted from blood samples and the assays were performed using next generation sequencing (NGS) and large rearrangement detection analysis, as previously described by Judkins et al. [33].

\subsection{Tumor Testing}

Molecular testing was retrospectively performed on snap frozen tumor samples that were collected prior to initiation of chemotherapeutic treatment. If frozen tumor tissue was unavailable, formalin-fixed paraffin embedded (FFPE) tissue was evaluated. BRCA1 promoter methylation levels were quantified using DNA methylation PCR arrays as previously described [21]. BRCA1/2 mutation screening was performed using custom hybridization enrichment and NGS on DNA from FFPE samples as described previously [34]. HRD score was determined by custom hybridization sequencing assay and was defined as the cumulative sum of whole-genome tumor loss of heterozygosity, telomeric allelic imbalance, and large-scale state transition, as described previously [24,25]. Tumor samples with HRD 
scores $\geq 42$ were considered to be HR deficient. Given that recent studies have suggested that lowering the HRD score cut-off from 42 to 33 may improve sensitivity to detecting a response to PARPi, HRD characterization and univariable/multivariable analyses were also performed with HR deficiency, as defined by HRD score threshold $\geq 33$ [35-38]. TMB was evaluated using a single nucleotide polymorphism-based resequencing assay, as previously described and validated [39]. MSI testing was performed as previously described [40].

Table 1. Demographic and clinical characteristics.

\begin{tabular}{|c|c|c|c|c|c|}
\hline \multirow[t]{2}{*}{ Clinicopathologic Characteristic } & \multicolumn{2}{|c|}{$\begin{array}{c}\text { PCS } \\
(n=128)\end{array}$} & \multicolumn{2}{|c|}{$\begin{array}{c}\text { NACT } \\
(n=172)\end{array}$} & \multirow[t]{2}{*}{$p$} \\
\hline & $\mathbf{N}$ & $\%$ & $\mathbf{N}$ & $\%$ & \\
\hline Age & \multirow{2}{*}{\multicolumn{2}{|c|}{$61(24-83)$}} & & & 0.625 \\
\hline Median (range) & & & \multicolumn{2}{|c|}{$62(25-95)$} & \\
\hline Race/ethnicity & & & & & 0.500 \\
\hline White & 97 & 75.8 & 123 & 72.4 & \\
\hline African American/Black & 5 & 3.9 & 13 & 7.6 & \\
\hline Asian & 9 & 7.0 & 15 & 8.8 & \\
\hline Hispanic & 17 & 13.3 & 19 & 11.2 & \\
\hline Unknown & 0 & 0 & 2 & $\mathrm{~N} / \mathrm{A}$ & \\
\hline Disease site & & & & & 0.022 \\
\hline Fallopian tube & 10 & 7.9 & 6 & 3.5 & \\
\hline Ovary & 95 & 75.4 & 117 & 68 & \\
\hline Peritoneum & 21 & 16.7 & 49 & 28.5 & \\
\hline Unknown & 2 & $\mathrm{~N} / \mathrm{A}$ & 0 & 0 & \\
\hline Stage & & & & & $<0.001$ \\
\hline In Situ & 1 & 0.8 & 0 & 0.0 & \\
\hline I & 11 & 9.2 & 0 & 0.0 & \\
\hline II & 13 & 10.8 & 1 & 0.7 & \\
\hline III & 82 & 68.3 & 72 & 53.3 & \\
\hline IV & 13 & 10.8 & 60 & 44.4 & \\
\hline Advanced & 0 & 0.0 & 2 & 1.5 & \\
\hline Unknown/unstaged & 8 & $\mathrm{~N} / \mathrm{A}$ & 37 & $\mathrm{~N} / \mathrm{A}$ & \\
\hline Histology & & & & & $<0.001$ \\
\hline \multicolumn{6}{|l|}{ Serous } \\
\hline High grade & 92 & 71.9 & 155 & 90.1 & \\
\hline Low grade & 16 & 12.5 & 12 & 6.9 & \\
\hline \multicolumn{6}{|l|}{ Endometrioid } \\
\hline High grade & 8 & 6.2 & 1 & 0.6 & \\
\hline Low grade & 1 & 0.8 & 0 & 0.0 & \\
\hline Clear cell & 9 & 7.0 & 2 & 1.2 & \\
\hline Adenocarcinoma NOS & 2 & 1.6 & 2 & 1.2 & \\
\hline Cytoreductive surgery & & & & & 0.356 \\
\hline Optimal & 103 & 92.0 & 139 & 88.5 & \\
\hline R0 & 70 & 68.0 & 90 & 57.3 & \\
\hline$\leq 1 \mathrm{~cm}$ & 18 & 16.1 & 29 & 18.5 & \\
\hline $\bar{N}$ ot specified & 15 & 13.4 & 20 & 12.7 & \\
\hline Suboptimal (>1 cm) & 9 & 8.0 & 18 & 11.5 & \\
\hline Unknown & 16 & $\mathrm{~N} / \mathrm{A}$ & 15 & $\mathrm{~N} / \mathrm{A}$ & \\
\hline Follow-up (months) & & & & & 0.870 \\
\hline Alive at time of analysis & 68 & $53.1 \%$ & 45 & $26.2 \%$ & \\
\hline Median (range) & \multicolumn{2}{|c|}{$79.1(18.6-114.9)$} & \multicolumn{2}{|c|}{$79.2(9.3-105.4)$} & \\
\hline
\end{tabular}

$\mathrm{N} / \mathrm{A}=$ not applicable. NACT = neoadjuvant chemotherapy. NOS = not otherwise specified. PCS = primary cytoreductive surgery. $\mathrm{R} 0=$ no macroscopic residual tumor. Note: cases with "unknown" characteristics are not included in percentages shown. N/A = not applicable. NACT = neoadjuvant chemotherapy. NOS = not otherwise specified. PCS = primary cytoreductive surgery. R0 = no macroscopic residual tumor. 


\subsection{Clinical Data Collection}

Clinical data were extracted from electronic medical records, including age, race/ethnicity, center, stage, tumor grade, histology, residual disease volume following surgery, chemotherapy cycles, recurrence, and death. Study data were collected and managed using REDCap (Research Electronic Data Capture) electronic data capture tools hosted at MD Anderson [41].

\subsection{Statistical Analysis}

Descriptive statistics were used to summarize the demographic and clinical characteristics of the study population. Overall survival (OS) was measured from date of surgery to date of death or last follow-up. Patients alive were censored at date of last follow-up. Median follow-up was defined as the median time from date of initial treatment (PCS or NACT) to date of last follow-up among those who were alive at the last follow-up visit. PFS was measured from date of surgery to the date of earliest recurrence, progression, or death. Patients were censored on the date of last evaluation for recurrence or progressive disease. The product limit estimator of Kaplan and Meier was used to estimate OS and PFS and modeled via Cox proportional hazards regression as a function of prognostic factors to estimate the hazard ratio with $95 \%$ confidence intervals. Separate multivariable models were constructed adjusting for age, stage, histology, and debulking status; low-grade histologic subtypes were excluded from these multivariable models. Exploratory subset analyses were conducted separately within the HGS subset. All statistical analyses were performed using Stata/MP v16.0 (College Station, TX, USA).

\section{Results}

\subsection{Patient Population}

A total of 300 EOC patients were enrolled meeting study criteria (Figure 1). Of the 300 patients, 128 patients (42.7\%) underwent PCS and the remaining 172 patients $(57.3 \%)$ underwent NACT followed by interval cytoreductive surgery (Figure 1).

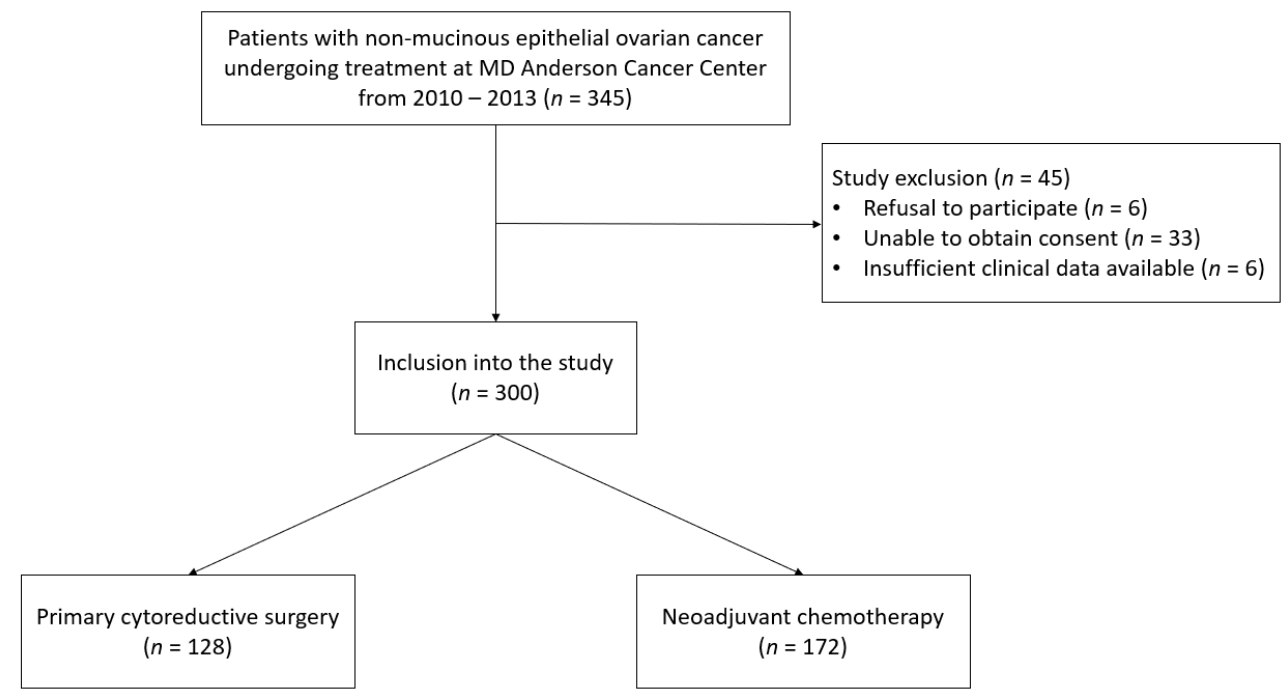

Figure 1. Flow diagram of patient population.

The study period predated PARPi approvals for frontline maintenance therapy and thus none of the patients received this treatment. Demographic and clinical characteristics of the full cohort of 300 patients are described in Table 1. In the PCS cohort, the median age was 61 years (range 24-83), with a median follow-up of 79.1 months (range 18.6-114.9). The majority of patients had advanced stage disease (79.8\%) and HGS histology (71.9\%). Information regarding residual tumor volume following PCS was available for 112 patients. Optimal cytoreduction occurred in 103 of 112 patients (92\%) with 70 achieving no residual disease (R0), 18 having residual disease $\leq 1 \mathrm{~cm}$ as the largest tumor diameter, and 15 cases 
were unspecified. There were differences in stages between the PCS and NACT cohorts $(p<0.001)$. The NACT cohort had a greater proportion of stage III/IV patients $(80.1 \% \mathrm{vs}$. $97.7 \%$ ). Additionally, there were differences in histology subtypes between the PCS and NACT cohorts $(p<0.001)$. The NACT cohort had a greater proportion of HGS histology (71.9\% vs. $90.1 \%$, respectively) and a smaller proportion of endometrioid $(7.0 \%$ vs. $0.6 \%)$ and clear cell ( $7.0 \%$ vs. $1.2 \%)$ histology. Molecular characterization focused on the PCS cohort due to the general availability of abundant pretreatment tumor tissue.

\subsection{Characterization of $H R D, M S I$, and TMB}

Molecular testing characteristics for the overall PCS cohort are shown in Table 2 and Figures 2 and 3 . Among patients who underwent PCS with completed BRCA1/2 germline testing, there were 17 patients (13.9\%) with germline BRCA1/2 mutations (10 BRCA1 and 7 BRCA2). Suspected deleterious or deleterious germline mutations in other non-BRCA1/2 mutations in the HR pathway were present in five of 85 patients $(5.9 \%)$ and included BRIP1 $(n=2)$, ATM $(n=2)$, and NBN $(n=1)$. Molecular testing of tumor tissue identified an additional five and three patients with somatic BRCA1 and BRCA2 mutations, respectively. BRCA1 promoter methylation was present in seven patients $(7.5 \%)$. The vast majority of ovarian tumors had microsatellite stability $(96.4 \%)$ and low TMB (98.9\%) (Appendix A Table A1). Microsatellite instability was identified in one case, which included clear cell histology and high TMB (30.4 mutations/megabase). MSI testing failed for three patients $(2.7 \%)$ (Table A1). HRD score testing was attempted in 108 patients with completed testing in $95(88.0 \%)$. Failed testing was most commonly due to low tumor cellularity in the testing specimen. Details of detected mutations associated with HRD are shown in Figures 2 and 3.

Table 2. Molecular testing characteristics in patients undergoing PCS.

\begin{tabular}{|c|c|}
\hline Germline Testing & $n(\%)$ \\
\hline \multicolumn{2}{|l|}{ gBRCA1/2 status $(n=122)$} \\
\hline gBRCA1/2 negative & $105(86.1 \%)$ \\
\hline gBRCA1 mutation ${ }^{1}$ & $10(8.2 \%)$ \\
\hline gBRCA2 mutation ${ }^{1}$ & $7(5.7 \%)$ \\
\hline \multicolumn{2}{|l|}{ Other HR gene mutations $(n=85)$} \\
\hline BRIP1 & $2(2.4 \%)$ \\
\hline ATM & $2(2.4 \%)$ \\
\hline NBN & $1(1.2 \%)$ \\
\hline MMR gene mutations $^{2}(n=85)$ & $0(0 \%)$ \\
\hline \multicolumn{2}{|l|}{ Other germline mutations $(n=85)$} \\
\hline MUTYH & $2(2.4 \%)$ \\
\hline Tumor testing & $n(\%)$ \\
\hline \multicolumn{2}{|l|}{ sBRCA1/2 status $(n=68)$} \\
\hline sBRCA1/2 negative & $59(86.7 \%)$ \\
\hline sBRCA1 mutation & $5(7.4 \%)$ \\
\hline sBRCA2 mutation & $3(4.4 \%)$ \\
\hline \multicolumn{2}{|l|}{ BRCA1 promoter methylation $(n=93)$} \\
\hline$\geq 15 \%$ & $7(7.5 \%)$ \\
\hline$<15 \%$ & $86(92.5 \%)$ \\
\hline \multicolumn{2}{|l|}{ HRD score $(n=95)$} \\
\hline$\geq 42$ & $42(44.2 \%)$ \\
\hline$\geq 33$ & $50(52.6 \%)$ \\
\hline
\end{tabular}

${ }^{1} 16$ of 16 patients with a germline BRCA1/2 mutation (10 BRCA1 and 6 BRCA2) with both germline and tumor BRCA1/2 testing results confirmed their respective germline mutations in the tumor. One patient with a germline BRCA2 mutation did not undergo somatic BRCA1/2 testing. ${ }^{2}$ Includes MLH1, MSH2, MSH6, PMS2, EPCAM. gBRCA1 $/ 2=$ germline BRCA1 $/ 2$ mutation. $\mathrm{HR}=$ homologous recombination. $\mathrm{HRD}=$ homologous recombination deficiency. $\mathrm{MMR}=$ mismatch repair. $\mathrm{sBRCA} 1 / 2=$ somatic BRCA1 $/ 2$ mutation. $\mathrm{PCS}=$ primary cytoreductive surgery. 


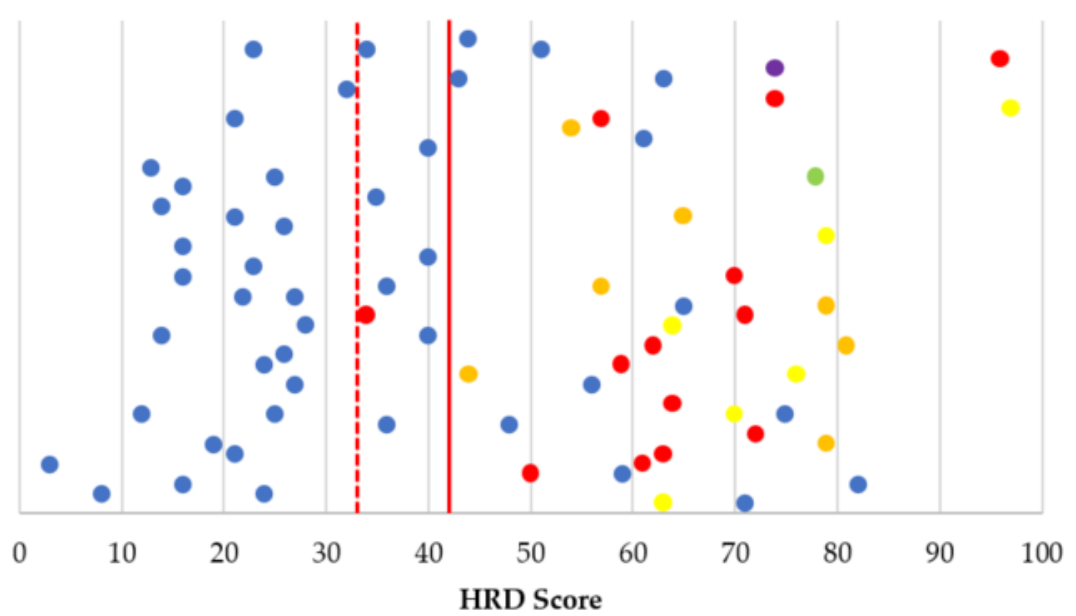

BRCA1/2 germline mutation $\quad$ BRCA1 promoter methylation
BRCA1/2 somatic mutation $\quad$ BRIP1 germline mutation

Figure 2. HRD score values and their associated HR defects in high-grade serous histology $(n=74)$. $\mathrm{HR}=$ homologous recombination. $\mathrm{HRD}=$ homologous recombination deficiency. HRD score cutoff threshold was defined as $\geq 42$ (red solid line). HRD score values above this threshold line were considered high HRD scores (HR deficient tumors) and values below the threshold line were considered low HRD scores (HR proficient tumors). An HRD score cut-off threshold $\geq 33$ (red dotted line) was also evaluated. Please note that values on the $y$-axis have been scattered to allow easier visualization of the HRD score datapoints. There is no variable on the $y$-axis.
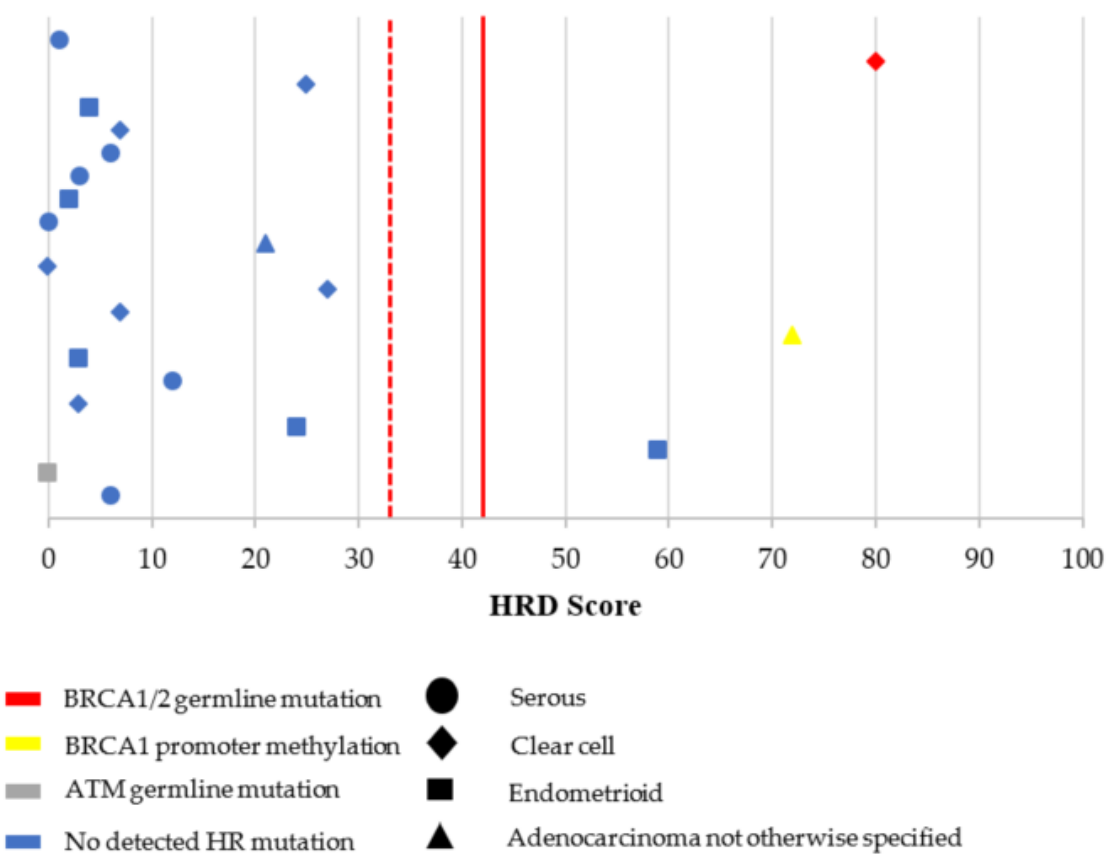

Figure 3. HRD score values and their associated HR defects in non-high-grade serous histology $(n=21) . \mathrm{HR}=$ homologous recombination. HRD = homologous recombination deficiency. HRD score cut-off threshold was defined as $\geq 42$ (red solid line). HRD score values above this threshold line were considered high HRD scores (HR deficient tumors) and values below the threshold line were considered low HRD scores (HR proficient tumors). An HRD score cut-off threshold $\geq 33$ (red dotted line) was also evaluated. Please note that values on the $y$-axis have been scattered to allow easier visualization of the HRD score datapoints. There is no variable on the $y$-axis. 
Among HGS cases with complete HRD characterization and an HRD score $\geq 42,9$ of 17 patients $(52.9 \%)$ had an associated cause for HRD (four germline BRCA1, two germline BRCA2, one somatic BRCA2, and two BRCA1 promoter methylation). When evaluating an HRD score $\geq 33$, a total of 20 patients had complete HRD characterization and had an HRD score $\geq 33$; however, no specific HR defects were determined in these three additional cases from our panel of molecular features.

Examining the non-HGS histology cases, there were 3 out of 21 (14.3\%) patients with an HRD score $\geq 42$ (Figure 3 ). These cases included one case with clear cell histology (HRD score of 80 and associated with a germline BRCA1 mutation), one case with adenocarcinoma not otherwise specified (HRD score of 72 and BRCA1 promoter methylation), and one case with endometrioid histology (HRD score of 59, but somatic BRCA1/2 and germline HR testing was not performed). There were no additional patients with non-HGS histology who met the criteria for HRD when the HRD score threshold was lowered to 33.

Overall, among all patients with successful HRD score testing $(n=95)$, there were 50 patients who met the criteria of HRD based on HRD score ( $\geq 33)$. Among the 50 patients with negative germline and somatic BRCA1/2 results (34 HGS and 16 non-HGS) and successful HRD score testing, there were 20 with HRD scores $\geq 33$.

\subsection{Survival}

Univariable analyses for OS and PFS for patients undergoing PCS are described in Tables A2 and A3, respectively. Overall, the median OS and PFS was 84.3 (95\% CI 66.2-not reached) and 23.6 (17.3-36.1) months, respectively. As anticipated, younger age (<65 years), early stage, and optimal cytoreduction were associated with improved OS and PFS (Tables A2 and A3). Any BRCA1/2 mutation was associated with improved OS (HR 0.36, 95\% CI 0.17-0.77; $p=0.008$ ) and PFS (HR 0.56, 95\% CI 0.33-0.98; $p=0.041$ ). OS and PFS univariable analyses based on HRD score threshold are described in Tables 3 and 4, respectively.

Table 3. Overall survival in patients undergoing PCS by HRD score.

\begin{tabular}{|c|c|c|c|c|c|c|}
\hline Characteristic & $\mathbf{N}$ & $\begin{array}{c}\text { Overall }(n=128) \\
\text { Hazard Ratio } \\
(95 \% \text { CI })\end{array}$ & $p$ & $\mathbf{N}$ & $\begin{array}{c}\text { HGS }(n=92) \\
\text { Hazard Ratio } \\
(95 \% \text { CI })\end{array}$ & $p$ \\
\hline \multicolumn{7}{|l|}{ HRD score } \\
\hline$<42$ & 53 & Ref & & 35 & Ref & \\
\hline$\geq 42$ & 42 & $0.63(0.35-1.12)$ & 0.118 & 39 & $0.48(0.26-0.90)$ & 0.021 \\
\hline \multicolumn{7}{|l|}{ HRD score } \\
\hline$<33$ & 45 & Ref & & 27 & Ref & \\
\hline$\geq 33$ & 50 & $0.51(0.29-0.90)$ & 0.019 & 47 & $0.31(0.17-0.58)$ & $<0.001$ \\
\hline \multicolumn{7}{|l|}{$\begin{array}{l}\text { Any HRD (HRD } \\
\text { score }>42)^{1}\end{array}$} \\
\hline No & 42 & Ref & & 26 & Ref & \\
\hline Yes & 49 & $0.59(0.33-1.05)$ & 0.074 & 45 & $0.45(0.24-0.85)$ & 0.014 \\
\hline \multicolumn{7}{|l|}{$\begin{array}{l}\text { Any HRD (HRD } \\
\text { score } \geq 33)^{2}\end{array}$} \\
\hline No & 36 & Ref & & 20 & Ref & \\
\hline Yes & 56 & $0.49(0.27-0.87)$ & 0.014 & 52 & $0.29(0.15-0.55)$ & $<0.001$ \\
\hline
\end{tabular}

HGS = high-grade serous. HRD = homologous recombination deficiency. PCS = primary cytoreductive surgery 1 Any HRD = germline or somatic BRCA1/2 mutation, germline non-BRCA1/2 homologous recombination deficiency mutation, BRCA1 promoter methylation $(\geq 15)$, and / or HRD score $\geq 42) .{ }^{2}$ Any HRD = germline or somatic BRCA1/2 mutation, germline non-BRCA1/2 homologous recombination deficiency mutation, BRCA1 promoter methylation ( $\geq 15)$, and/or HRD score $\geq 33$ ).

Although an HRD score $\geq 42$ was not associated with differences in OS nor PFS, an HRD score $\geq 33$ was associated with improved OS (HR 0.51, 95\% CI 0.29-0.90; $p=0.019$ ) (Table 3 and Figure 4). 
Table 4. Progression-free survival in patients undergoing PCS by HRD score.

\begin{tabular}{|c|c|c|c|c|c|c|}
\hline Characteristic & $\mathbf{N}$ & $\begin{array}{c}\text { Overall }(n=128) \\
\text { Hazard Ratio }(95 \% \text { CI) }\end{array}$ & $p$ & $\mathbf{N}$ & $\begin{array}{c}\text { HGS }(n=92) \\
\text { Hazard Ratio }(95 \% \text { CI) }\end{array}$ & $p$ \\
\hline \multicolumn{7}{|l|}{ HRD score } \\
\hline$<42$ & 53 & Ref & & 35 & Ref & \\
\hline$\geq 42$ & 41 & $0.75(0.47-1.21)$ & 0.246 & 38 & $0.57(0.34-0.95)$ & 0.033 \\
\hline \multicolumn{7}{|l|}{ HRD score } \\
\hline $\begin{array}{l}<33 \\
>33\end{array}$ & $\begin{array}{l}45 \\
49\end{array}$ & $\begin{array}{c}\text { Ref } \\
0.72(0.45-1.16)\end{array}$ & 0.177 & $\begin{array}{l}27 \\
46\end{array}$ & $\begin{array}{c}\text { Ref } \\
0.46(0.27-0.77)\end{array}$ & 0.003 \\
\hline \multicolumn{7}{|l|}{$\begin{array}{l}\text { Any HRD (HRD } \\
\text { score }>42)^{1}\end{array}$} \\
\hline No & 42 & Ref & & 26 & Ref & \\
\hline & 48 & $0.71(0.44-1.16)$ & 0.170 & 54 & $0.57(0.33-0.98)$ & 0.044 \\
\hline \multicolumn{7}{|l|}{$\begin{array}{l}\text { Any HRD (HRD } \\
\text { score }>33)^{2}\end{array}$} \\
\hline No & 36 & Ref & & 20 & Ref & \\
\hline Yes & 55 & $0.66(0.41-1.07)$ & 0.092 & 51 & $0.43(0.24-0.75)$ & 0.003 \\
\hline
\end{tabular}

HGS = high-grade serous. HRD = homologous recombination deficiency. PCS = primary cytoreductive surgery ${ }^{1}$ Any HRD (HRD score $\geq 42$ ) = germline or somatic BRCA1/2 mutation, germline non-BRCA1/2 homologous recombination deficiency mutation, BRCA1 promoter methylation ( $\geq 15)$, and/or HRD score $\geq 42) .{ }^{2}$ Any HRD $($ HRD score $\geq 33)$ = germline or somatic BRCA1/2 mutation, germline non-BRCA1/2 homologous recombination deficiency mutation, BRCA1 promoter methylation $(\geq 15)$, and/or HRD score $\geq 33)$.

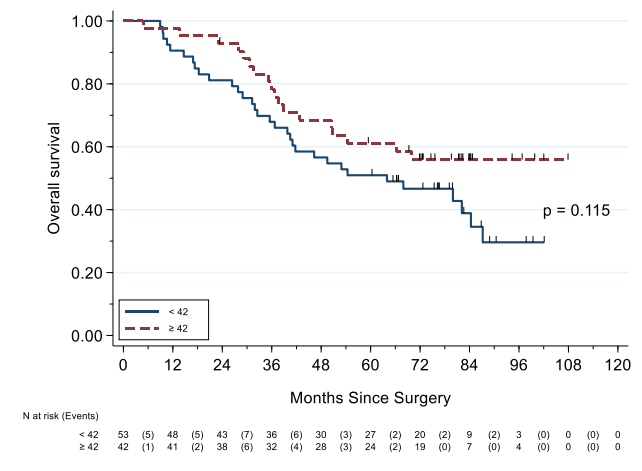

(a)

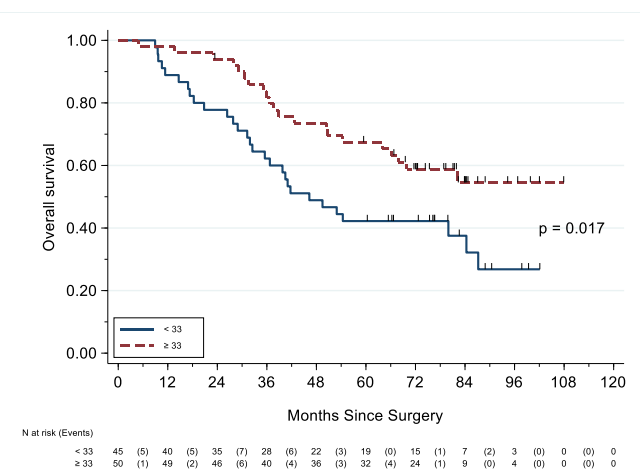

(b)

Figure 4. Overall survival based on HRD score threshold. (a) Overall survival based on HRD score threshold of 42; (b) overall survival based on HRD score threshold of 33 .

Subgroup univariable analyses for patients with HGS tumors are also shown in Tables 3, 4, A2 and A3. Again as expected, patients with HGS tumors who were younger in age, in an early stage, had optimal cytoreduction, or had any BRCA1/2 mutation had improved OS and PFS (Tables A2 and A3). An HRD score $\geq 42$ was associated with improved OS (HR 0.48, 95\% CI 0.26-0.90; $p=0.021$ ) and PFS (HR 0.57, 95\% CI 0.34-0.95; $p=0.033$ ) among HGS tumors (Tables 3 and 4). Similarly, an HRD score $\geq 33$ was also associated with improved OS (HR 0.31, 95\% CI 0.17-0.58; $p<0.001$ ) and PFS (HR 0.46, 95\% CI 0.27-0.77; $p=0.003$ ) (Tables 3 and 4).

Results of the multivariable analyses are shown in Table 5. Excluding low-grade tumors, the multivariable model adjusted for age, stage, histology, and debulking status. An HRD score $\geq 33$ (HR 0.43, 95\% CI 0.23-0.81; $p=0.009$ ) or any HR defects (with HRD score $\geq 33$ ) (HR $0.45,95 \%$ CI $0.23-0.89 ; p=0.022$ ) were significantly associated with improved OS when adjusting for age, stage, histology, and debulking status. For PFS, any BRCA1/2 mutation was associated with improved outcome (HR 0.47, 95\% CI 0.24-0.92; $p=0.028)$. 
Table 5. Multivariable model for overall and progression-free survival.

\begin{tabular}{|c|c|c|c|c|c|c|}
\hline Characteristic & $\mathbf{N}$ & $\begin{array}{c}\text { Overall Survival } \\
\text { Hazard Ratio }(95 \% \text { CI) }\end{array}$ & $p$ & $\mathbf{N}$ & $\begin{array}{c}\text { Progression-Free Survival } \\
\text { Hazard Ratio (95\% CI) }\end{array}$ & $p$ \\
\hline $\begin{array}{l}\text { Any BRCA1 } \\
\text { mutation }\end{array}$ & 67 & $0.76(0.31-1.89)$ & 0.557 & 67 & $0.63(0.29-1.35)$ & 0.233 \\
\hline $\begin{array}{l}\text { Any BRCA2 } \\
\text { mutation } \\
\text { Any }\end{array}$ & 84 & $0.19(0.03-1.41)$ & 0.105 & 84 & $0.51(0.18-1.42)$ & 0.194 \\
\hline $\begin{array}{l}\text { BRCA1/2 } \\
\text { mutation }\end{array}$ & 68 & $0.44(0.19-1.02)$ & 0.054 & 68 & $0.47(0.24-0.92)$ & 0.028 \\
\hline $\begin{array}{l}\text { gNon-BRCA } \\
\text { HR mutation }\end{array}$ & 62 & $0.93(0.26-3.34)$ & 0.908 & 62 & $1.15(0.33-4.09)$ & 0.825 \\
\hline $\begin{array}{l}\text { HRD score } \\
\geq 42\end{array}$ & 78 & $0.69(0.36-1.30)$ & 0.250 & 77 & $0.72(0.42-1.24)$ & 0.233 \\
\hline $\begin{array}{l}\overline{\mathrm{H}} \mathrm{RD} \text { score } \\
\geq 33\end{array}$ & 78 & $0.43(0.23-0.81)$ & 0.009 & 77 & $0.62(0.36-1.06)$ & 0.078 \\
\hline $\begin{array}{l}\text { BRCA1p } \\
\text { methylation } \\
\geq 15 \\
\text { Any HRD }\end{array}$ & 70 & $1.41(0.49-4.00)$ & 0.522 & 69 & $1.11(0.38-3.23)$ & 0.841 \\
\hline $\begin{array}{l}\text { (HRD score } \\
\geq 42)^{1} \\
\text { Any HRD }\end{array}$ & 73 & $0.68(0.34-1.33)$ & 0.260 & 71 & $0.70(0.38-1.27)$ & 0.240 \\
\hline $\begin{array}{l}\text { (HRD score } \\
\geq 33)^{2}\end{array}$ & 72 & $0.45(0.23-0.89)$ & 0.022 & 72 & $0.60(0.33-1.08)$ & 0.087 \\
\hline \multicolumn{7}{|c|}{$\begin{array}{l}\text { gNon-BRCA HR mutation = germline non-BRCA1/2 homologous recombination deficiency mutation. HR } \\
=\text { homologous recombination. } \mathrm{HR}=\text { homologous recombination deficiency. BRCA1p = BRCA1 promoter. } \\
\text { Multivariable model adjusted for age, stage, histology, and debulking status; low-grade histologic subtypes were } \\
\left.\text { excluded from the models. }{ }^{1} \text { Any HRD (HRD score } \geq 42\right)=\text { germline or somatic BRCA1/2 mutation, germline } \\
\text { non-BRCA1 } / 2 \text { homologous recombination deficiency mutation, BRCA1 promoter methylation }(\geq 15) \text {, and } / \text { or } \\
\left.\text { HRD score } \geq 42) .{ }^{2} \text { Any HRD (HRD score } \geq 33\right)=\text { germline or somatic BRCA1/2 mutation, germline non-BRCA1/2 } \\
\text { homologous recombination deficiency mutation, BRCA1 promoter methylation }(\geq 15) \text {, and/or HRD score } \geq 33 \text { ). }\end{array}$} \\
\hline
\end{tabular}

\section{Discussion}

With growing clinical need and interest in molecular tumor assays in the management of EOC, we sought to characterize HRD biomarkers, MSI, and TMB and determine their associations with survival outcomes. Given the potential clinical impact of the HRD score assay, evaluation in multiple study populations is essential. We evaluated the impact of lowering the HRD score threshold from 42 to 33, given that retrospective studies have suggested that such a cutoff may improve sensitivity in detecting responses and benefits to platinum-containing agents and/or PARPi [35-38]. Both HRD score thresholds of 42 or 33 were associated with improved OS and PFS among patients with HGS tumors in univariable analyses. However, compared to the previously used threshold of 42, the lower threshold of 33 remained significantly associated with improved OS among all patients in univariable and multivariable analyses. Additionally, in multivariable analyses, improved PFS for those with HRD scores $\geq 33$ approached statistical significance.

After lowering the HRD score threshold to 33, there were an additional 8 patients (making a total of 50 patients) who met the criteria of HRD based on HRD score alone, out of a total of 95 with completed HRD score testing. Among the 95 patients with complete HRD score testing, there were also 50 with negative germline and somatic BRCA1/2 results (34 HGS and 16 non-HGS), with 20 having high HRD scores. Thus, based on the findings in this study, HRD score testing could help identify a substantial number of patients with HRD beyond patients that would be identified with BRCA1/2 testing alone. Furthermore, among those with HRD testing, there was interestingly only one patient with an HR defect who did not have a high HRD score $\geq 33$ (a patient with endometrioid histology, ATM germline mutation, and an HRD score of 0 ). Although ATM plays an early role in the HR pathway, there is evidence that ATM-deficient cells may still have overall functional HR pathways (albeit delayed kinetics) with sensitivity to PARPi because ATM is postulated to also regulate response to double-strand DNA breaks at multiple levels and inhibit error prone nonhomologous end joining $[42,43]$. This mechanism may explain the low HRD score in the aforementioned patient with a germline ATM mutation.

Given the growing importance of immunotherapy in solid tumors and the need to establish biomarkers to predict responses, we evaluated MSI and TMB in the EOC population undergoing PCS. In our study, we observed only one MSI tumor (clear cell 
histology) out of 107 (0.9\%) EOC tumors with successful MSI testing. This finding is consistent with the other studies that have reported an MSI prevalence of approximately $1-2 \%[44,45]$. A meta-analysis and systematic review by Pal and colleagues highlighted the wide range in the prevalence of MSI in $977 \mathrm{EOC}$ patients in 18 studies ranging from $0 \%$ to $36.7 \%$ [46] and a pooled frequency of $12 \%(95 \%$ CI $8-17 \%)$, but the variations in reported prevalence may be related to interstudy differences, including study population heterogeneity, histologic subtypes evaluated, or detection methods [45,46]. Additionally, we observed TMB to be low in nearly all our patients except for the same patient with an MSI tumor. Other studies have reported TMB to be lower in EOC compared to other tumors but that it may be increased in tumors in the presence of HR defects [47,48]. It is difficult to comment on the relevance of MSI and TMB status on prognosis given that the overwhelming majority of tumors did not demonstrate MSI and had low TMB. In the literature, there have been mixed results regarding MSI and TMB for EOC patients with MSI tumors $[49,50]$. Future studies should investigate MSI and TMB in the non-HGS EOC population.

As expected, factors such as younger age, early stage, optimal cytoreduction, or presence of BRCA1/2 mutations were associated with improved OS and PFS (especially for HGS patients) and these prognosticators have been reported in the literature [51,52]. We did not observe any association between BRCA1 promoter methylation and survival and it is difficult to assess the impact of BRCA1 promoter methylation in this study given the small number of cases with methylation $(n=7)$. Unlike germline or somatic BRCA1/2 mutations, BRCA1 promoter methylation as a prognosticator has been reported with mixed results [53-55]. Similar to BRCA1 promoter methylation in this study, there were few cases of germline non-BRCA1/2 HR mutations and this likely impacted the ability to observe a favorable association with survival outcomes. This result is in contrast with the results of molecular analyses of samples from patients enrolled in the larger GOG 218 trial $(n=307)$, where the investigators observed non-BRCA1/2 HR-related mutations to be a favorable prognosticator [20].

The utilization of HRD score testing in clinical trials evaluating PARPi therapy has highlighted the assay's potential clinical benefit to EOC patients. In a phase III, doubleblind randomized control trial (PRIMA), patients with HRD score $\geq 42$ had improved PFS when treated with niraparib compared to placebo (HR 0.50, 95\% CI 0.31-0.83) in the frontline setting [56]. In a phase II, single-arm QUADRA trial, Moore and colleagues observed an objective response rate of $26 \%$ to niraparib for recurrent, platinum-sensitive EOC patients with HRD scores $\geq 42$ (compared to $4 \%$ in the HR proficient or unknown group) on subgroup analysis [27]. The results of the QUADRA trial led to FDA approval of niraparib monotherapy for patients with platinum-sensitive tumors and a high HRD scores in the recurrent setting. Additionally, a phase III PAOLA-1 trial investigated the use of bevacizumab (anti-VEGF monoclonal antibody) and olaparib maintenance compared to placebo/bevacizumab maintenance in advanced stage EOC in the frontline setting [26]. In a subgroup analysis of patients with an HRD score $\geq 42$, the median PFS was improved in the olaparib/bevacizumab arm compared to the placebo/bevacizumab arm (28.1 vs. 16.6 months; HR 0.31, 95\% CI 0.20-0.47) [26]. Based on these results, the addition of olaparib to bevacizumab maintenance in the frontline setting received FDA approval in May 2020 for patients with advanced EOC and HR deficient tumors that are responsive to platinum-based chemotherapy and bevacizumab. In a phase III VELIA trial, patients with advanced HGS ovarian cancer in the frontline setting were placed in three arms: chemotherapy with placebo and placebo maintenance (control), chemotherapy with velaparib followed by placebo maintenance (velaparib-combination only), and chemotherapy with velaparib followed by velaparib maintenance (velaparib-throughout) [36]. The trial designated HRD scores $\geq 33$ as HR deficiency, given that retrospective analyses had demonstrated a subset of patients with HRD scores below 42 who derived some PFS benefit when treated with PARPi $[35,37,38]$. The VELIA investigators demonstrated an HRD score $\geq 33$ was associated with improved PFS (HR 0.80, 95\% CI 0.64-0.997) when treated 
with velaparib-throughout compared to placebo [36]. These aforementioned clinical trials highlighted the importance of HRD score testing as a tool to identify patients likely to benefit from PARPi therapy. Biomarkers such as germline/somatic BRCA1/2, germline non-BRCA1/2 mutations, and BRCA1 promoter methylation may not fully capture defects in the HR pathway. Thus, genomic signatures captured through HRD assays can potentially expand the benefit of PARPi to more EOC patients.

One of the strengths of this study was the follow-up period for the study population of 79.1 months (range 18.6-114.9 months). A long follow-up period improves the ability to detect differences in OS based on biomarker status. Furthermore, this study evaluated multiple biomarker surrogates for HRD in order to evaluate evidence of HRD. Additionally, this cohort had a larger than usual representation of Hispanic patients $(13.3 \%$ compared to typically 4\%) [20,57]. This study has several limitations. Molecular analyses could not be uniformly performed on all cases. When performing molecular analyses, blood or tissue samples were not always sufficient to complete germline non-BRCA1/2 HR-related mutation, BRCA1 promoter methylation, or HRD score testing. In addition, because only pretreatment core biopsies were available for patients in the NACT cohort, these specimens were reserved for clinical care and this research study focused exclusively on the PCS cohort. Furthermore, PCS and NACT populations may vary across institutions due to different practice patterns, which may influence the generalizability of these findings. Additionally, given the longitudinal nature of the study, long-term survival outcomes may also be influenced by differences in treatment regimens following frontline therapy. Furthermore, as discussed earlier, the clinical impact of studied prognosticators may also be modified in the current landscape of greater PARPi use. In addition, there were low numbers of endometrioid, clear cell, and low-grade serous tumors for HRD characterization. This representation was expected given that HGS tumors represent the great majority of EOC. Lastly, while the HRD $\geq 42$ group did not show a statistically significant association with overall survival in the Kaplan-Meier analysis or multivariable models, it is possible that evaluation in a larger cohort of cases would have greater statistical power to determine an association. Nevertheless, it is important to note that the hazard ratios for the HRD $\geq 33$ group showed consistently significant HRD effects compared to the HRD $\geq 42$ group. In the multivariable models, evaluation of these two different cutoffs again showed a significant HRD effect using the HRD $\geq 33$ cutoff but not when using the HRD $\geq 42$ cutoff (Table 5).

\section{Conclusions}

In conclusion, EOC management is becoming increasingly individualized as molecular features guide treatment stratification. The HRD score assay provides a valuable adjunctive tool to capture evidence of HRD that may be missed if only germline HR and somatic BRCA1/2 testing are performed. An HRD score threshold $\geq 33$, compared to the currently used threshold of $\geq 42$, has a strong association with improved overall survival. This new threshold may serve to better prognosticate patients with EOC and has the potential to expand the number of candidates who could receive PARPi as an alternative treatment option. Future studies are needed to compare the predictive ability of both these thresholds on PARPi therapeutic benefit.

Author Contributions: Conceptualization, K.H.L., K.S. and M.S.Y.; methodology, J.A.H., B.F., Y.Y., M.S.D., K.S., K.T., J.S.L. and M.S.Y.; software, B.F. and M.S.Y.; validation, J.A.H., A.A.J., B.F., Y.Y., M.S.D., K.T., J.S.L., S.P., C.S. and M.S.Y.; formal analysis, B.F., Y.Y., K.T., S.P., C.S. and M.S.Y.; investigation, J.A.H., A.A.J., K.H.L., K.T., J.S.L. and M.S.Y.; resources, K.T., K.H.L. and M.S.Y.; data curation, J.A.H., K.T. and M.S.Y.; writing-original draft preparation, J.A.H. and M.S.Y.; writing-review and editing, J.A.H., A.A.J., B.F., Y.Y., M.S.D., K.S., K.T., J.S.L., S.P., C.S., K.H.L. and M.S.Y.; visualization, J.A.H. and M.S.Y.; supervision, A.A.J., K.H.L. and M.S.Y.; project administration, J.A.H. and M.S.Y.; funding acquisition, K.T., K.H.L. and M.S.Y. All authors have read and agreed to the published version of the manuscript.

Funding: This research was supported in part by the National Institutes of Health (NIH) T32 training grant (T32 CA101642) (J.A.H.), the Cedars Cancer Foundation/Dr. Henry R. Shibata Fellowship 
Award (J.A.H.), and the MD Anderson Cancer Center Support Grant (CA016672) that supports the Biostatistics Resource Group and Tissue Biospecimen and Pathology Resource Group.

Institutional Review Board Statement: The study was conducted according to the guidelines of the Declaration of Helsinki, and approved by the Institutional Review Board of the University of Texas MD Anderson Cancer Center (protocol LAB09-800 approved on 11/23/2009).

Informed Consent Statement: Informed consent was obtained from all subjects involved in the study.

Data Availability Statement: A portion of de-identified data presented in this study may be made available on request from the corresponding author. The data was stored in a secure database using REDCap (Research Electronic Data Capture) electronic data capture tools hosted at the University of Texas MD Anderson Cancer Center.

Acknowledgments: A preliminary version of this research report was previously presented at the 2017 Annual Meeting of the American Society for Clinical Oncology [58].

Conflicts of Interest: The authors from MD Anderson Cancer Center report no conflicts of interest directly related to this study. Myriad Genetics, Inc. did not provide funding to MD Anderson investigators for this study. Outside of this study, A.A.J reports personal fees from Gerson and Lehrman Group, Guidepoint, Iovance Advisory Board, Nuprobe, Simcere, Pact Pharma, and unrelated research funding from AstraZeneca, Bristol Myers Squibb, Iovance, Aravive, Pfizer, Immatics USA, and Eli Lilly. K.T., J.S.L., S.P., and C.S. are employees of, and hold stock in, Myriad Genetics, Inc. Funding agencies had no role in the design of the study; in the collection, analyses, or interpretation of data; in the writing of the manuscript; or in the decision to publish the results.

\section{Appendix A}

Table A1. Microsatellite instability and tumor mutational burden testing in patients undergoing PCS.

\begin{tabular}{|c|c|}
\hline Tumor Testing & $n(\%)$ \\
\hline \multicolumn{2}{|l|}{ MSI status $(n=110)$} \\
\hline MSS & $106(96.4 \%)$ \\
\hline MSI & $1(0.9 \%)$ \\
\hline Failed testing & $3(2.7 \%)$ \\
\hline \multicolumn{2}{|l|}{$\operatorname{TMB}(n=94)$} \\
\hline Median (range) & $1.82(0-30.4)$ \\
\hline Low & $93(98.9 \%)$ \\
\hline High & $1(1.1 \%)$ \\
\hline
\end{tabular}

MSI = microsatellite instability. MSS = microsatellite stable. PCS = primary cytoreductive surgery. TMB = tumor mutational burden. 
Table A2. Overall survival in patients undergoing PCS.

\begin{tabular}{|c|c|c|c|c|c|c|}
\hline Characteristic & $\mathbf{N}$ & $\begin{array}{c}\text { Hazard Ratio } \\
\text { (95\% CI) }\end{array}$ & $p$ & $\mathbf{N}$ & $\begin{array}{l}\text { Hazard Ratio } \\
(95 \% \text { CI })\end{array}$ & $p$ \\
\hline \multicolumn{7}{|l|}{ Age } \\
\hline$<65$ & 76 & Ref & & 50 & Ref & \\
\hline$\geq 65$ & 52 & $2.57(1.54-4.27)$ & $<0.001$ & 42 & $2.88(1.64-5.07)$ & $<0.001$ \\
\hline \multicolumn{7}{|l|}{ Stage } \\
\hline I/II & 25 & Ref & & 14 & Ref & \\
\hline III/IV & 95 & $9.58(2.33-39.37)$ & 0.002 & 73 & $6.44(1.56-26.58)$ & 0.010 \\
\hline \multicolumn{7}{|l|}{ Residual disease after } \\
\hline \multicolumn{7}{|l|}{ PCS } \\
\hline Optimal & 103 & Ref & & 74 & Ref & \\
\hline Suboptimal $(>1 \mathrm{~cm})$ & 9 & $4.16(1.93-8.95)$ & $<0.001$ & 7 & 3.57 (1.47-8.65) & 0.005 \\
\hline \multicolumn{7}{|l|}{ Any BRCA1 mutation } \\
\hline No & 69 & Ref & & 44 & Ref & \\
\hline Yes & 21 & $0.56(0.25-1.26)$ & 0.160 & 19 & $0.35(0.15-0.85)$ & 0.020 \\
\hline \multicolumn{7}{|l|}{ Any BRCA2 mutation } \\
\hline No & 108 & Ref & & 74 & Ref & \\
\hline Yes & 10 & $0.15(0.02-1.08)$ & 0.059 & 10 & $0.11(0.01-0.79)$ & 0.029 \\
\hline \multicolumn{7}{|l|}{ Any BRCA1/2 } \\
\hline No & 62 & Ref & & 37 & Ref & \\
\hline Yes & 31 & $0.36(0.17-0.77)$ & 0.008 & 29 & $0.19(0.08-0.44)$ & $<0.001$ \\
\hline \multicolumn{7}{|l|}{ gNon-BRCA HR } \\
\hline \multicolumn{7}{|l|}{ mutation } \\
\hline Negative & 80 & Ref & & 53 & Ref & \\
\hline Positive & 5 & $1.97(0.70-5.59)$ & 0.200 & 4 & $1.95(0.68-5.58)$ & 0.214 \\
\hline \multicolumn{7}{|l|}{$\begin{array}{l}\text { BRCA1 promoter } \\
\text { methylation }\end{array}$} \\
\hline$<15$ & 86 & Ref & & 60 & Ref & \\
\hline$\geq 15$ & 7 & $1.14(0.41-3.17)$ & 0.804 & 6 & $0.68(0.21-2.20)$ & 0.516 \\
\hline
\end{tabular}

gNon-BRCA HR mutation = germline non-BRCA1/2 homologous recombination mutation. HGS = high-grade serous. $\mathrm{HR}=$ homologous recombination. $\mathrm{HRD}=$ homologous recombination deficiency. $\mathrm{PCS}=$ primary cytoreductive surgery.

Table A3. Progression-free survival in patients undergoing PCS.

\begin{tabular}{|c|c|c|c|c|c|c|}
\hline Characteristic & $\mathbf{N}$ & $\begin{array}{c}\text { Overall }(n=128) \\
\text { Hazard Ratio }(95 \% \text { CI })\end{array}$ & $p$ & $\mathbf{N}$ & $\begin{array}{c}\text { HGS }(n=92) \\
\text { Hazard Ratio }(95 \% \text { CI })\end{array}$ & $p$ \\
\hline \multicolumn{7}{|l|}{ Age } \\
\hline$<65$ & 75 & Ref & & 49 & Ref & \\
\hline$\geq 65$ & 52 & $1.87(1.22-2.86)$ & 0.004 & 42 & $1.82(1.14-2.91)$ & 0.012 \\
\hline \multicolumn{7}{|l|}{$\overline{\text { Stage }}$} \\
\hline $\mathrm{I} / \mathrm{II}$ & 25 & Ref & & 14 & Ref & \\
\hline III/IV & 94 & $2.98(1.53-5.81)$ & 0.001 & 72 & $2.17(1.04-4.29)$ & 0.038 \\
\hline \multicolumn{7}{|l|}{ Residual disease after } \\
\hline \multicolumn{7}{|l|}{ PCS } \\
\hline Optimal & 102 & Ref & & 73 & Ref & \\
\hline Suboptimal $(>1 \mathrm{~cm})$ & 9 & 4.15 (1.97-8.72) & $<0.001$ & 7 & $3.10(1.35-7.08)$ & 0.007 \\
\hline \multicolumn{7}{|l|}{ Any BRCA1 mutation } \\
\hline No & 69 & Ref & & 44 & Ref & \\
\hline Yes & 21 & $0.70(0.38-1.29)$ & 0.254 & 19 & $0.47(0.24-0.90)$ & 0.023 \\
\hline \multicolumn{7}{|l|}{ Any BRCA2 mutation } \\
\hline No & 108 & Ref & & 74 & Ref & \\
\hline Yes & 10 & $0.51(0.20-1.26)$ & 0.143 & 10 & $0.35(0.14-0.87)$ & 0.025 \\
\hline \multicolumn{7}{|l|}{$\begin{array}{l}\text { Any BRCA1/2 } \\
\text { mutation }\end{array}$} \\
\hline $\begin{array}{l}\text { mutation } \\
\text { No }\end{array}$ & 62 & Ref & & 37 & Ref & \\
\hline Yes & 31 & $0.56(0.33-0.98)$ & 0.041 & 29 & $0.30(0.16-0.54)$ & $<0.001$ \\
\hline \multicolumn{7}{|l|}{ gNon-BRCA HR } \\
\hline Negative & 80 & Ref & & 53 & Ref & \\
\hline Positive & 5 & $1.85(0.67-5.11)$ & 0.237 & 4 & $2.99(1.06-8.47)$ & 0.039 \\
\hline \multicolumn{7}{|l|}{ BRCA1 promoter } \\
\hline$<15$ & 85 & Ref & & 59 & Ref & \\
\hline$\geq 15$ & 7 & $0.78(0.28-2.15)$ & 0.633 & 6 & $0.49(0.15-1.57)$ & 0.229 \\
\hline
\end{tabular}

gNon-BRCA HR mutation = germline non-BRCA1/2 homologous recombination deficiency mutation. HGS $=$ high-grade serous. $\mathrm{HR}=$ homologous recombination. HRD $=$ homologous recombination deficiency. PCS = primary cytoreductive surgery.

\section{References}

1. Siegel, R.L.; Miller, K.D.; Jemal, A. Cancer statistics, 2020. CA Cancer J. Clin. 2020, 70, 7-30. [CrossRef]

2. Matulonis, U.A. Management of newly diagnosed or recurrent ovarian cancer. Clin. Adv. Hematol. Oncol. $2018,16,426-437$.

3. McGuire, W.P.; Hoskins, W.J.; Brady, M.F.; Kucera, P.R.; Partridge, E.E.; Look, K.Y.; Clarke-Pearson, D.L.; Davidson, M. Cyclophosphamide and cisplatin compared with paclitaxel and cisplatin in patients with stage III and stage IV ovarian cancer. N. Engl. J. Med. 1996, 334, 1-6. [CrossRef] 
4. $\quad$ Ozols, R.F.; Bundy, B.N.; Greer, B.E.; Fowler, J.M.; Clarke-Pearson, D.; Burger, R.A.; Mannel, R.S.; DeGeest, K.; Hartenbach, E.M.; Baergen, R. Phase III trial of carboplatin and paclitaxel compared with cisplatin and paclitaxel in patients with optimally resected stage III ovarian cancer: A Gynecologic Oncology Group study. J. Clin. Oncol. 2003, 21, 3194-3200. [CrossRef]

5. Ledermann, J.A.; Drew, Y.; Kristeleit, R.S. Homologous recombination deficiency and ovarian cancer. Eur. J. Cancer 2016, 60, 49-58. [CrossRef] [PubMed]

6. The Cancer Genome Atlas Research Network. Integrated genomic analyses of ovarian carcinoma. Nature 2011, 474, 609-615. [CrossRef]

7. Hoeijmakers, J.H. Genome maintenance mechanisms for preventing cancer. Nature 2001, 411, 366-374. [CrossRef] [PubMed]

8. Trenner, A.; Sartori, A.A. Harnessing DNA Double-Strand Break Repair for Cancer Treatment. Front. Oncol. 2019, 9, 1388. [CrossRef]

9. Wang, Y.; Cortez, D.; Yazdi, P.; Neff, N.; Elledge, S.J.; Qin, J. BASC, a super complex of BRCA1-associated proteins involved in the recognition and repair of aberrant DNA structures. Genes Dev. 2000, 14, 927-939.

10. Yuan, S.S.; Lee, S.Y.; Chen, G.; Song, M.; Tomlinson, G.E.; Lee, E.Y. BRCA2 is required for ionizing radiation-induced assembly of Rad51 complex in vivo. Cancer Res. 1999, 59, 3547-3551. [PubMed]

11. Kelland, L. The resurgence of platinum-based cancer chemotherapy. Nat. Rev. Cancer 2007, 7, 573-584. [CrossRef] [PubMed]

12. Konstantinopoulos, P.A.; Ceccaldi, R.; Shapiro, G.I.; D'Andrea, A.D. Homologous Recombination Deficiency: Exploiting the Fundamental Vulnerability of Ovarian Cancer. Cancer Discov. 2015, 5, 1137-1154. [CrossRef] [PubMed]

13. Farmer, H.; McCabe, N.; Lord, C.J.; Tutt, A.N.; Johnson, D.A.; Richardson, T.B.; Santarosa, M.; Dillon, K.J.; Hickson, I.; Knights, C.; et al. Targeting the DNA repair defect in BRCA mutant cells as a therapeutic strategy. Nature 2005, 434, 917-921. [CrossRef]

14. Helleday, T. The underlying mechanism for the PARP and BRCA synthetic lethality: Clearing up the misunderstandings. Mol. Oncol. 2011, 5, 387-393. [CrossRef] [PubMed]

15. Hoppe, M.M.; Sundar, R.; Tan, D.S.P.; Jeyasekharan, A.D. Biomarkers for Homologous Recombination Deficiency in Cancer. J. Natl. Cancer Inst. 2018, 110, 704-713. [CrossRef] [PubMed]

16. Coleman, R.L.; Oza, A.M.; Lorusso, D.; Aghajanian, C.; Oaknin, A.; Dean, A.; Colombo, N.; Weberpals, J.I.; Clamp, A.; Scambia, G.; et al. Rucaparib maintenance treatment for recurrent ovarian carcinoma after response to platinum therapy (ARIEL3): A randomised, double-blind, placebo-controlled, phase 3 trial. Lancet 2017, 390, 1949-1961. [CrossRef]

17. Pujade-Lauraine, E.; Ledermann, J.A.; Selle, F.; Gebski, V.; Penson, R.T.; Oza, A.M.; Korach, J.; Huzarski, T.; Poveda, A.; Pignata, S.; et al. Olaparib tablets as maintenance therapy in patients with platinum-sensitive, relapsed ovarian cancer and a BRCA1/2 mutation (SOLO2/ENGOT-Ov21): A double-blind, randomised, placebo-controlled, phase 3 trial. Lancet Oncol. 2017, 18, 1274-1284. [CrossRef]

18. Ledermann, J.; Harter, P.; Gourley, C.; Friedlander, M.; Vergote, I.; Rustin, G.; Scott, C.L.; Meier, W.; Shapira-Frommer, R.; Safra, T.; et al. Olaparib maintenance therapy in patients with platinum-sensitive relapsed serous ovarian cancer: A preplanned retrospective analysis of outcomes by BRCA status in a randomised phase 2 trial. Lancet Oncol. 2014, 15, 852-861. [CrossRef]

19. Mirza, M.R.; Monk, B.J.; Herrstedt, J.; Oza, A.M.; Mahner, S.; Redondo, A.; Fabbro, M.; Ledermann, J.A.; Lorusso, D.; Vergote, I.; et al. Niraparib Maintenance Therapy in Platinum-Sensitive, Recurrent Ovarian Cancer. N. Engl. J. Med. 2016, 375, 2154-2164. [CrossRef]

20. Norquist, B.M.; Brady, M.F.; Harrell, M.I.; Walsh, T.; Lee, M.K.; Gulsuner, S.; Bernards, S.S.; Casadei, S.; Burger, R.A.; Tewari, K.S.; et al. Mutations in Homologous Recombination Genes and Outcomes in Ovarian Carcinoma Patients in GOG 218: An NRG Oncology/Gynecologic Oncology Group Study. Clin. Cancer Res. 2018, 24, 777-783. [CrossRef]

21. Abkevich, V.; Timms, K.M.; Hennessy, B.T.; Potter, J.; Carey, M.S.; Meyer, L.A.; Smith-McCune, K.; Broaddus, R.; Lu, K.H.; Chen, J.; et al. Patterns of genomic loss of heterozygosity predict homologous recombination repair defects in epithelial ovarian cancer. Br. J. Cancer 2012, 107, 1776-1782. [CrossRef] [PubMed]

22. Birkbak, N.J.; Wang, Z.C.; Kim, J.Y.; Eklund, A.C.; Li, Q.; Tian, R.; Bowman-Colin, C.; Li, Y.; Greene-Colozzi, A.; Iglehart, J.D.; et al. Telomeric allelic imbalance indicates defective DNA repair and sensitivity to DNA-damaging agents. Cancer Discov. 2012, 2, 366-375. [CrossRef] [PubMed]

23. Popova, T.; Manie, E.; Rieunier, G.; Caux-Moncoutier, V.; Tirapo, C.; Dubois, T.; Delattre, O.; Sigal-Zafrani, B.; Bollet, M.; Longy, M.; et al. Ploidy and large-scale genomic instability consistently identify basal-like breast carcinomas with BRCA1/2 inactivation. Cancer Res. 2012, 72, 5454-5462. [CrossRef]

24. Timms, K.M.; Abkevich, V.; Hughes, E.; Neff, C.; Reid, J.; Morris, B.; Kalva, S.; Potter, J.; Tran, T.V.; Chen, J.; et al. Association of BRCA1/2 defects with genomic scores predictive of DNA damage repair deficiency among breast cancer subtypes. Breast Cancer Res. 2014, 16, 475. [CrossRef]

25. Telli, M.L.; Timms, K.M.; Reid, J.; Hennessy, B.; Mills, G.B.; Jensen, K.C.; Szallasi, Z.; Barry, W.T.; Winer, E.P.; Tung, N.M.; et al. Homologous Recombination Deficiency (HRD) Score Predicts Response to Platinum-Containing Neoadjuvant Chemotherapy in Patients with Triple-Negative Breast Cancer. Clin. Cancer Res. 2016, 22, 3764-3773. [CrossRef] [PubMed]

26. Ray-Coquard, I.; Pautier, P.; Pignata, S.; Pérol, D.; González-Martín, A.; Berger, R.; Fujiwara, K.; Vergote, I.; Colombo, N.; Mäenpää, J.; et al. Olaparib plus Bevacizumab as First-Line Maintenance in Ovarian Cancer. N. Engl. J. Med. 2019, 381, 2416-2428. [CrossRef] 
27. Moore, K.N.; Secord, A.A.; Geller, M.A.; Miller, D.S.; Cloven, N.; Fleming, G.F.; Wahner Hendrickson, A.E.; Azodi, M.; DiSilvestro, P.; Oza, A.M.; et al. Niraparib monotherapy for late-line treatment of ovarian cancer (QUADRA): A multicentre, open-label, single-arm, phase 2 trial. Lancet Oncol. 2019, 20, 636-648. [CrossRef]

28. Le, D.T.; Durham, J.N.; Smith, K.N.; Wang, H.; Bartlett, B.R.; Aulakh, L.K.; Lu, S.; Kemberling, H.; Wilt, C.; Luber, B.S.; et al. Mismatch repair deficiency predicts response of solid tumors to PD-1 blockade. Science 2017, 357, 409-413. [CrossRef]

29. Pećina-Šlaus, N.; Kafka, A.; Salamon, I.; Bukovac, A. Mismatch Repair Pathway, Genome Stability and Cancer. Front. Mol. Biosci. 2020, 7, 122. [CrossRef]

30. Marabelle, A.; Le, D.T.; Ascierto, P.A.; Di Giacomo, A.M.; De Jesus-Acosta, A.; Delord, J.-P.; Geva, R.; Gottfried, M.; Penel, N.; Hansen, A.R.; et al. Efficacy of Pembrolizumab in Patients With Noncolorectal High Microsatellite Instability/Mismatch Repair-Deficient Cancer: Results From the Phase II KEYNOTE-158 Study. J. Clin. Oncol. 2019, 38, 1-10. [CrossRef]

31. Matulonis, U.A.; Shapira-Frommer, R.; Santin, A.D.; Lisyanskaya, A.S.; Pignata, S.; Vergote, I.; Raspagliesi, F.; Sonke, G.S.; Birrer, M.; Provencher, D.M.; et al. Antitumor activity and safety of pembrolizumab in patients with advanced recurrent ovarian cancer: Results from the phase II KEYNOTE-100 study. Ann. Oncol. 2019, 30, 1080-1087. [CrossRef]

32. Goodman, A.M.; Kato, S.; Bazhenova, L.; Patel, S.P.; Frampton, G.M.; Miller, V.; Stephens, P.J.; Daniels, G.A.; Kurzrock, R. Tumor Mutational Burden as an Independent Predictor of Response to Immunotherapy in Diverse Cancers. Mol. Cancer Ther. 2017, 16, 2598-2608. [CrossRef]

33. Judkins, T.; Leclair, B.; Bowles, K.; Gutin, N.; Trost, J.; McCulloch, J.; Bhatnagar, S.; Murray, A.; Craft, J.; Wardell, B.; et al. Development and analytical validation of a 25-gene next generation sequencing panel that includes the BRCA1 and BRCA2 genes to assess hereditary cancer risk. BMC Cancer 2015, 15, 215. [CrossRef]

34. Hennessy, B.T.; Timms, K.M.; Carey, M.S.; Gutin, A.; Meyer, L.A.; Flake, D.D., 2nd; Abkevich, V.; Potter, J.; Pruss, D.; Glenn, P.; et al. Somatic mutations in BRCA1 and BRCA2 could expand the number of patients that benefit from poly (ADP ribose) polymerase inhibitors in ovarian cancer. J. Clin. Oncol. 2010, 28, 3570-3576. [CrossRef] [PubMed]

35. Hodgson, D.R.; Dougherty, B.A.; Lai, Z.; Fielding, A.; Grinsted, L.; Spencer, S.; O'Connor, M.J.; Ho, T.W.; Robertson, J.D.; Lanchbury, J.S.; et al. Candidate biomarkers of PARP inhibitor sensitivity in ovarian cancer beyond the BRCA genes. Br. J. Cancer 2018, 119, 1401-1409. [CrossRef] [PubMed]

36. Coleman, R.L.; Fleming, G.F.; Brady, M.F.; Swisher, E.M.; Steffensen, K.D.; Friedlander, M.; Okamoto, A.; Moore, K.N.; Efrat Ben-Baruch, N.; Werner, T.L.; et al. Veliparib with First-Line Chemotherapy and as Maintenance Therapy in Ovarian Cancer. N. Engl. J. Med. 2019, 381, 2403-2415. [CrossRef]

37. Telli, M.L.; Metzger, O.; Timms, K.; Evans, B.; Vogel, D.; Wei, H.; Jones, J.T.; Wenstrup, R.J.; McKee, M.D.; Sullivan, D.M.; et al. Evaluation of homologous recombination deficiency (HRD) status with pathological response to carboplatin $+/$ - veliparib in BrighTNess, a randomized phase 3 study in early stage TNBC. J. Clin. Oncol. 2018, 36, 519. [CrossRef]

38. Stronach, E.A.; Paul, J.; Timms, K.M.; Hughes, E.; Brown, K.; Neff, C.; Perry, M.; Gutin, A.; El-Bahrawy, M.; Steel, J.H.; et al. Biomarker Assessment of HR Deficiency, Tumor BRCA1/2 Mutations, and CCNE1 Copy Number in Ovarian Cancer: Associations with Clinical Outcome Following Platinum Monotherapy. Mol. Cancer Res. 2018, 16, 1103-1111. [CrossRef]

39. Timms, K.; Zharkikh, A.; Perry, M.; Birkbak, N.; Szallasi, Z.; Gutin, A.; Richardson, A.; Lanchbury, J. Comparison between whole exome sequencing (WES) and single nucleotide polymorphism (SNP)-based tumor mutation burden analysis. J. Clin. Oncol. 2019, 37, 2634. [CrossRef]

40. Siedel, J.H.; Ring, K.L.; Hu, W.; Dood, R.L.; Wang, Y.; Baggerly, K.; Gallagher, S.; Tshiaba, P.; Neff, C.; Timms, K.M.; et al. Clinical Significance of Homologous Recombination Deficiency Score Testing in Endometrial Cancer. Gynecol. Oncol. 2021. (manuscript in-press). [CrossRef] [PubMed]

41. Harris, P.A.; Taylor, R.; Thielke, R.; Payne, J.; Gonzalez, N.; Conde, J.G. Research electronic data capture (REDCap)-a metadatadriven methodology and workflow process for providing translational research informatics support. J. Biomed. Inform. 2009, 42, 377-381. [CrossRef]

42. Balmus, G.; Pilger, D.; Coates, J.; Demir, M.; Sczaniecka-Clift, M.; Barros, A.C.; Woods, M.; Fu, B.; Yang, F.; Chen, E.; et al. ATM orchestrates the DNA-damage response to counter toxic non-homologous end-joining at broken replication forks. Nat. Commun. 2019, 10, 87. [CrossRef]

43. Bakr, A.; Oing, C.; Köcher, S.; Borgmann, K.; Dornreiter, I.; Petersen, C.; Dikomey, E.; Mansour, W.Y. Involvement of ATM in homologous recombination after end resection and RAD51 nucleofilament formation. Nucleic Acids Res. 2015, 43, 3154-3166. [CrossRef] [PubMed]

44. Bonneville, R.; Krook, M.A.; Kautto, E.A.; Miya, J.; Wing, M.R.; Chen, H.Z.; Reeser, J.W.; Yu, L.; Roychowdhury, S. Landscape of Microsatellite Instability Across 39 Cancer Types. JCO Precis. Oncol. 2017, 1, 1-15. [CrossRef]

45. Deshpande, M.; Romanski, P.A.; Rosenwaks, Z.; Gerhardt, J. Gynecological Cancers Caused by Deficient Mismatch Repair and Microsatellite Instability. Cancers 2020, 12. [CrossRef]

46. Pal, T.; Permuth-Wey, J.; Kumar, A.; Sellers, T.A. Systematic review and meta-analysis of ovarian cancers: Estimation of microsatellite-high frequency and characterization of mismatch repair deficient tumor histology. Clin. Cancer Res. 2008, 14, 6847-6854. [CrossRef]

47. Morse, C.B.; Elvin, J.A.; Gay, L.M.; Liao, J.B. Elevated tumor mutational burden and prolonged clinical response to anti-PD-L1 antibody in platinum-resistant recurrent ovarian cancer. Gynecol. Oncol. Rep. 2017, 21, 78-80. [CrossRef] [PubMed] 
48. Strickland, K.C.; Howitt, B.E.; Shukla, S.A.; Rodig, S.; Ritterhouse, L.L.; Liu, J.F.; Garber, J.E.; Chowdhury, D.; Wu, C.J.; D'Andrea, A.D.; et al. Association and prognostic significance of BRCA1/2-mutation status with neoantigen load, number of tumor-infiltrating lymphocytes and expression of PD-1/PD-L1 in high grade serous ovarian cancer. Oncotarget 2016, 7, 13587-13598. [CrossRef]

49. Segev, Y.; Zhang, S.; Akbari, M.R.; Sun, P.; Sellers, T.A.; McLaughlin, J.; Risch, H.A.; Rosen, B.; Shaw, P.; Schildkraut, J.; et al. Survival in women with ovarian cancer with and without microsatellite instability. Eur. J. Gynaecol. Oncol. 2015, 36, 681-684. [PubMed]

50. Bi, F.; Chen, Y.; Yang, Q. Significance of tumor mutation burden combined with immune infiltrates in the progression and prognosis of ovarian cancer. Cancer Cell Int. 2020, 20, 373. [CrossRef]

51. Chan, J.K.; Loizzi, V.; Lin, Y.G.; Osann, K.; Brewster, W.R.; DiSaia, P.J. Stages III and IV invasive epithelial ovarian carcinoma in younger versus older women: What prognostic factors are important? Obstet. Gynecol. 2003, 102, 156-161. [CrossRef]

52. Bristow, R.E.; Tomacruz, R.S.; Armstrong, D.K.; Trimble, E.L.; Montz, F.J. Survival effect of maximal cytoreductive surgery for advanced ovarian carcinoma during the platinum era: A meta-analysis. J. Clin. Oncol. 2002, 20, 1248-1259. [CrossRef]

53. Cass, I.; Baldwin, R.L.; Varkey, T.; Moslehi, R.; Narod, S.A.; Karlan, B.Y. Improved survival in women with BRCA-associated ovarian carcinoma. Cancer 2003, 97, 2187-2195. [CrossRef]

54. Long, K.C.; Kauff, N.D. Hereditary ovarian cancer: Recent molecular insights and their impact on screening strategies. Curr. Opin. Oncol. 2011, 23, 526-530. [CrossRef]

55. Moschetta, M.; George, A.; Kaye, S.B.; Banerjee, S. BRCA somatic mutations and epigenetic BRCA modifications in serous ovarian cancer. Ann. Oncol. 2016, 27, 1449-1455. [CrossRef]

56. González-Martín, A.; Pothuri, B.; Vergote, I.; DePont Christensen, R.; Graybill, W.; Mirza, M.R.; McCormick, C.; Lorusso, D.; Hoskins, P.; Freyer, G.; et al. Niraparib in Patients with Newly Diagnosed Advanced Ovarian Cancer. N. Engl. J. Med. 2019, 381, 2391-2402. [CrossRef]

57. Norquist, B.M.; Harrell, M.I.; Brady, M.F.; Walsh, T.; Lee, M.K.; Gulsuner, S.; Bernards, S.S.; Casadei, S.; Yi, Q.; Burger, R.A.; et al. Inherited Mutations in Women With Ovarian Carcinoma. JAMA Oncol. 2016, 2, 482-490. [CrossRef]

58. Yates, M.S.; Timms, K.; Daniels, M.S.; Oakley, H.D.; Munsell, M.F.; Lanchbury, J.S.; Lu, K.H. Evaluation of BRCA1/2 and homologous recombination defects in ovarian cancer and impact on clinical outcomes. J. Clin. Oncol. 2017, 35, 5511. [CrossRef] 